\title{
EDITORIAL
}

\section{Innovation or fraud?}

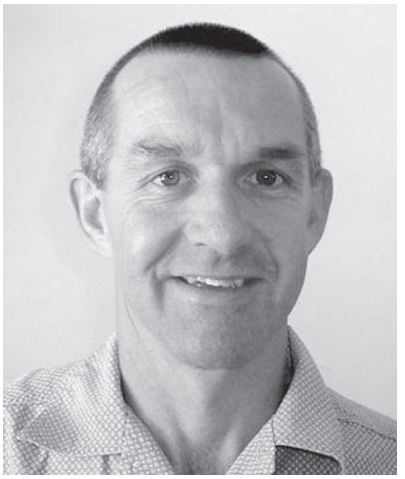

I was recently asked for my opinion about a proposal which was submitted to an administrative body which controlled high-performance sport. This proposal described a 'patented' method which purported to be able to optimise physical training, physical therapy, weight loss, injury detection and treatment and other health care applications. In other words, this simple, non-invasive measurement was supposed to do what a team of highly trained support staff members should be doing. Too good to be true? Or entrepreneurs at work using pseudo-science as their marketing tool?

It was interesting to read how the proposal had been compiled and it confirmed my belief that some people are very skilful at trying to dupe consumers into purchasing something that is really worthless. In reading the proposal I realised that the first step of the pseudo-scientists is to manufacture a profile. This is done by having several letters after their names implying many years of postgraduate study. Furthermore, the address of the 'director' is often listed as that of a consultant at a nondescript institute. This elevated profile is an attempt to gain the readers' confidence before the next step in the process can be approached.

The next step usually involves a bombardment of statistics which are often meaningless and for which there is no means of verification. This ostensibly gives the product credibility. This step is followed by a strategy which is also designed to gain the readers' confidence and includes a detailed pseudoscientific description of what the test can possibly do. This is usually written in a confusing style clearly taking to heart the old saying: 'If you cannot dazzle them with brilliance, baffle them with $b^{* * * * *} t$ '. Typically the reader is bombarded with several references of published studies. A closer examination of the references will show that they have absolutely nothing to do with the product. However, a cursory read of the article with all the references cited at the end will certainly influence someone into thinking that the product is really supported by a large body of published material.

The next step in this skilful marketing exercise is to state some unrealistic claims of what the product can do. While this strategy is well known in the weight-loss industry, it is starting to become more popular in the exercise health and fitness industry where claims of miraculous recovery from training and injury are being made. At present there is no body that can legislate over false advertising, particularly when it comes to claims about exercise. While there are some vigilant groups that monitor adverts about nutritional products and weight-loss products there are no groups that complain when products are marketed under the guise of being a miraculous adjunct to exercise training. Clearly this is a gap in the market that some shrewd business people have observed. As health professionals coming from an evidence-based background the duty falls on all of us to be observant and not fall into the traps which these skilful pseudo-scientists have set.

At present, when it comes to improving exercise performance it can be said with confidence that there is no magic formula that is going to work better than a systematic approach to training and adequate recovery coupled to innovative coaching. Anyone who claims to have a secret formula which works better than this approach is clearly trying to make a quick profit at someone else's expense.

This third edition of the South African Journal of Sports Medicine in 2007 has a variety of papers which should hopefully cover the interests of all the members of the South African Sports Medicine Association. This edition of the journal also includes an insert which presents a 'report card' related to health and fitness for school children in South Africa. The compilation of this report involved collaboration from scientists around the country. All the major relevant studies of schoolchildren in South Africa were included in the report and the data were translated into practical outcomes. This was a great exercise to bridge the communication gap between scientists, the media, educators and parents and is an exercise which should also be conducted in the services delivered under the broad umbrella of sports medicine.

\section{Mike Lambert \\ Editor-in-Chief}

